\title{
7. Macro, Micro, and Meta-Persuasive Play to Change Society
}

\author{
Lindsay D. Grace
}

\begin{abstract}
This chapter examines persuasive games through the dominant arguments made about the value of such designed play. Beyond the who, what, and where, there is the why. Why do researchers and practitioners want to persuade people through games? Why are games the right-or potentially wrong - medium for delivering persuasive messages? Why has public discourse come to need games as a vehicle for communicating and argumentation? Why has the design of such play grown into an increasingly media-rich environment that is seemingly adrift, unable to decant the real from its opposite?
\end{abstract}

Keywords: macro-persuasions; micro-persuasions; meta-persuasions; gamification; industry; play rhetoric

\section{Introduction}

This chapter examines persuasive games through the dominant arguments made about the value of such designed play. Beyond the who, what, and where, there is the why. Why do researchers and practitioners want to persuade people through games? Why are games the right —or potentially wrong - medium for delivering persuasive messages? Why has public discourse come to need games as a vehicle for communicating and argumentation? Why has the design of such play grown into an increasingly media-rich environment that is seemingly adrift, unable to decant the real from the unreal?

These questions are not the mere product of diegetic examination. Instead, they are drawn from the daily operations of directing a game studio at

Hera, T. Dela, J. Jansz, J. Raessens, B. Schouten, Persuasive Gaming in Context. Amsterdam: Amsterdam University Press, 2021 DOI 10.5117/9789463728805_CHO7 
the apex of the increasingly complicated political theater of Washington, DC, its interplay with democracy, and the dissemination of information. These questions are informed by contracted work and practiced research in purpose-driven games. This work is carried out for a variety of professional clients that include a number of the Smithsonian Museums, the World Bank, the International Finance Corporation (IFC), Education Testing Services (ETS), the U.S. National Institutes of Mental Health (NIMH), and several radio, television, and news organizations. The questions also relate to work to improve journalism through game design (Grace \& Farley, 2016) and projects for public and private media organizations.

In 2013, the American University Game Lab was founded with the mission to research, teach, and practice persuasive play. There are now several definitions of persuasive play and persuasive games. Bogost's version is the most commonly used (Bogost, 2007), but I prefer a marketing-inspired definition of persuasive play as games and other engagement strategies designed to change a player's interests, activities, or opinions. This definition converts the lifestyle segmentation used by demographers and market researchers (Plummer, 1974) toward games. It also carries a longer running tradition of assessment and efficacy analysis informed by more than 30 years of demographic and psychographic research. In the array of demographer tools, for instance, there are methods for understanding the current state of people's interests, activities, and opinions (Demby, 2011). Assessing the efficacy of any persuasive play engagement can proceed from gauging the pre-persuasive play and postpersuasive play state of those three attributes. Admittedly, these definitions are pragmatic and lack the academic inspiration of Bogost's seminal work.

I propose that there are three broad categories of persuasive play that are worthy not only of research but as foci for industrial practice. These are: macro-persuasions, micro-persuasions. and meta-persuasions. Macropersuasions are the efforts across gaming made about games and their relationship to society. Micro-persuasions are the games themselves that aim to employ persuasive play. Meta-persuasions, meanwhile, are the efforts, whether playful or nefarious, that act upon non-play systems as though they were systems. Meta-persuasions are the least obvious of the three, originating partly as the byproduct of macro and micro-persuasions, in part due to the absence of critical examination, and most obviously as the application of playful thinking to non-playful contexts. If purposeful games, persuasive games, or the much-debated serious games are applications of games in non-game contexts, meta-persuasions are their complement. Meta-persuasion is the application of play in non-play contexts, and it works against big data by producing big bad data (aka poorly constructed or fake 
data). It also works against the democratic function of real news by producing fake news or playing devil's advocate where no such advocate is required.

The characteristics of persuasive gaming preface each of these efforts. There is, for example, procedural rhetoric in macro and meta-persuasive levels and micro-persuasive games. The results of these persuasions do yield a byproduct, namely the unintended persuasion. Through a combination of case-study reports and position setting, this chapter outlines the proof, character, and exemplars of each of these persuasions.

The chapter focuses on macro-persuasion as a case study in how largescale efforts to change the interests, activities, and opinions of game players and non-players have been executed over the past decade. These efforts directly affect all of the persuasions. Macro-persuasions demonstrate a kind of application of persuasive play design in non-game contexts. They are not an application of gamification but instead a chorus of efforts designed to elevate the status and efficacy of games in general society.

The goals of this chapter are to help others in the persuasive games space examine these practices to refine their own work and develop appropriate strategies for combating the unintended results of such work, and to provide a topographic view of how such strategies might be applied elsewhere.

\section{The macro-persuasion}

There are several ways to frame persuasive games. At the macro level, they can be framed as a whole. This whole is comprised of the creative product of games, the practice of playing games, and the communities that orbit games. In this framework, games are a quantifiable, distinct, and discrete set. To make sense of this, games must be viewed as an artifact, and viewing them in this way requires framing them distinctly from one or more of the following lenses:

- Games are the artifact of game design and development; or

- Games are a cultural artifact of leisure; or

- Games are the creative artifact of contemporary expression; or

- Games are the artifact with which players interact.

A game as an artifact is supported by these or any of the other ways in which games can be described as a product not of a commercial system but of humanity. Being an artifact of humanity or humanness focuses its value and the claims thereto. 
The macro-persuasions are centered on making claims about games in general. Often, such persuasions contain arguments made for the inherent value - or lack of value - of games. This includes organizations that aim to legitimize the cultural capital and significance of games, game-makers, and their players. In the past decade, a chorus has grown to persuade the world that games are more than 'mere' entertainment, with supporters typically championing the value of games as cultural artifacts (Greenfield, 1994) and as a means to support and form a community (Squire, 2011), foster citizen participation (De Lange, 2015), express creativity (Jenkins, 2005), or practice desired skills (Gee, 2004).

This is not a new persuasive aim, but it is one that persists and for which the scale has grown. The hallmarks of this effort include everything from the Games for Change Festival (http://www.gamesforchange.org/), the many serious games conferences that take place, and the myriad of conventions, events, and other gatherings that aim to argue in favor of the value of the medium. They include the Institute of Play Inc. (https://www.instituteofplay. org/), the Institute for Play (http://www.nifplay.org/), the Higher Education Video Game Alliance (HEVGA), and others. These organizations and their efforts have proliferated in the years since Bogost first wrote his book, Persuasive Games (2007).

The impact of these organizations' efforts is arguably less significant than the effect of their mere existence. Regardless of how many awards are given, how many papers are published, or how many people convene to support the organizational efforts, the ability to hoist the banner of ten-year-old organizations and large conference attendances is clearly noteworthy. It is capable, though, of obscuring the relatively limited identifiable successes within persuasive play.

The mere fact that the Games for Change Festival, for example, has maintained audiences of at least 300 for more than a decade clearly emphasizes significant and persistent support for games of this type. The support of major private foundations, industry partners, and the public only further enhances the claims of the potential for such games. In the grand scheme of macro-persuasion, it means little that serious games, for example, continue to lack definition or widespread adoption. It is, instead, such a rhetoric-rich environment that much of the evidence is built more on the idea than the reality, which is a theme that has overshadowed a variety of major gatherings but has never dampened spirits or enthusiasm. Like all game players, we are unsure whether what we are doing is working, but we are working to do it all the same. Similar to learning how a game works, some action is often better than no action. Of course, the evidence of the more than 140 research 
studies published on such work demonstrates positive behavior change and outcomes (Boyle et al., 2016), meaning that there are grounds for optimism.

\section{Increasing the cultural capital of games}

Whether or not games have risen from the often-disposable world of popular culture to the more elite space of cultural contribution is arguable. We know, for example, that games have some cultural capital by being recognized at museums (Grace, 2017) and other respected institutions that offer markers of cultural worth. What is perhaps more important is to understand how this increase in reputation has occurred and at what cost.

There were few game-art exhibits of international note in 2007, but in 2017 there were 22 large-scale events offering games as culturally valuable and not just as industrial products of historical novelty. The growth can be attributed to the past success and an increased appetite for the genre. The rise in geek culture (King et al., 2003), the continued value of technical fields (aka STEM in contemporary parlance, which refers to science, technology, engineering, and mathematics), and a prolonged period of emerging adulthood that increasingly extends beyond adolescence (Arnett, 2002) are all plausible explanations for what seems to be a perceived increase in value for games as culturally respected artifacts.

Likewise, the rise of the gamer as an identity seems to indicate a status change, if not a fundamental argument in itself. Players have migrated toward player identities. Where once someone may have been an avid Space Invaders player, being a Minecraft (Duncan, 2011) player or firstperson shooter player comes with a community (Xu et al., 2011). Beyond the support of the Internet, player communities come with identities, affinity spaces, and privileges (Corneliussen, 2008). That these communities are privately managed, sometimes to the financial benefit of game-makers, is less important than the reality that such communities exist. The Game Developer's Conference, for example, which is the largest gathering of its kind, has supported a community management summit for years (http:// www.gdconf.com/conference/community.html), at which I have admittedly spoken.

Macro-persuasive procedural rhetoric is evidenced in the ways in which these groups aim to gain the cultural capital they seek. Most macro-persuasive play aims to mimic predecessors. The argument for games being an important and substantial industry once had a benchmark - more revenue than the movie industry (the reportedly outgoing dominant popular media 
industry). Nevertheless, once that benchmark was passed (Nath, 2016), games had to stand on their own and establish new standards of their own (Entertainment Software Association, 2015). The scale of the often-researched World of War Craft community, for example, offers the benefits of size and weight. At the game's popular height, these communities authored 297,496 pages of content (Wikia, 2017) and have been linked to positive social support (Longman et al., 2006) but have also shouldered the blame for a variety of game-related disasters, including child neglect.

Macro-persuasions not only come from federal, private, or public organizations; they also come from abhorrent, self-organized communities rallied around a few mantras. In the case of Gamer Gate (Parkin, 2014) and its widespread attacks, the macro-persuasion centered on some version of preserving games for gamers. The language of purity for games and real gamers sounds eerily similar to nativist and racist groups and is clearly anti-feminist (Chess \& Shaw, 2015). From the perspective of the supporters of Gamer Gate, games were a piece of their identity that needed to be protected, preserved, and defended from those who were seemingly attacking it (Salter, 2017).

Their strategies for winning this supposed culture war was a translation of that which they perceived from the outside as threatening. They produced pseudo-intellectual videos, outlining the errors in research produced by those they felt were attacking them, despite their own history of abuse (Salter, 2017). They also initiated investigations online, engaging in a somewhat television-like drama inspired by connecting disparate dots. At other times, their efforts wove intricate plots of espionage, funding, and conspiracy that were befitting of some of the most interesting games ever produced. They even rallied to participate in the academic processes of the organization at the center of much of their angst, the Digital Games Research Association (DiGRA). The community had planned to submit articles to the DiGRA annual conference, review papers, or even organize their own events.

The strategies for these individuals were primarily borrowed, i.e., they were strategies that bolstered the rhetoric of collusion in games or of an oppressed group of gamers who are having social justice games heft upon them unwillingly. In some ways, they followed Cialdini's weapons of influence (Cialdini, 1987), employing what was possible for a relatively unfunded group.

The persuasion comes from a few common mechanics for both ends of these persuasive game strategies. First, align games with something culturally valued. Second, mimic the characteristics of the signifiers for those culturally valued elements. Third, produce the evidence, through numbers and explanation, and then disseminate it to as wide an audience 
as possible, building a consensus first among those who already support your message.

These three steps can serve as a kind of playbook for effectively persuading society of the value of any enterprise. Although rather fundamental, this is a common strategy. It is, for example, why the logos and promotional elements of rising sports communities like World Quidditch and e-Sport's Major League Gaming look so eerily similar to Major League Baseball, the Olympics, or other well-regarded, culturally valued elements. True to the playbook, these formerly rising communities finish their rise with images and statistics to affirm their cultural value (i.e., 'If lots of people do it, it must be valuable'). This is the same logic that affirms the value of certain games conferences and e-sports.

If someone wants to employ macro-persuasions, the simplest strategy is to find an analogy to a respected cultural element, mimic that element, and then produce the evidence that there is a wide audience.

\section{The work of games, culture, and the rhetoric of production}

An important question to ask is whether games themselves have made the cultural rise or whether the labor in making them is really the element of rise. Unity, the makers of the software platform on which many game developers make their games, has seen far more financial success than the individual developers who subscribe to its services. The work of making games has continued to be attractive, despite the relatively low probability of it yielding either cultural or financial capital. Even for those games that are extremely valued, they rarely undergo the kinds of preservation efforts employed for other popular media (e.g., books and film). If the macro-persuasions have worked successfully and games have increased their cultural notoriety, why are there not more substantial efforts to preserve games?

While we argue that the work of making games is important, we rarely stop to ask about their preservation. This is in part because games have been, and continue to be, a disposable consumable, despite their rise toward the status of an artifact. We make games to feed our need to play. By analogy, the best games exist more like fine-dining experiences than high art. This is particularly evident in the ways we preserve games. To riff off of Bogost's keynote speech at the Games for Change Festival that talked about serious cheesecake, these games are treated like a decadent dessert we offer in two forms (Bogost, 2012): we either crystallize the game in its form, demonstrating it and isolating it from the larger space (like artificial food under glass and 
left in a window for display); or we offer it as a buffet to be consumed until players have gorged themselves until they are full. Game jams, for example, produce lots and lots of games, but their value is volume not quality.

Game jams are the bulk-value version of game manufacturing-lots of content with an emphasis on volume for cost purposes. Producing thousands of games in a single weekend offers the illusion of value. Admittedly, gamejam products are almost the inverse of bulk food. With bulk food, there is the occasional mistake. With game jams, there is the occasional success. This is, of course, completely fine, as the aim of a jam is not good product but good production. Jams are valued for their labor and their community, not for their process or the quality of their product.

The trick is that each of these efforts exists as a macro-persuasion. They each make distinct claims about games and their value to the society in which they exist. For several of these efforts that have blossomed in the last decade, there are simplified arguments to be witnessed in their practice. These are as follows:

\section{Game jams}

Game jams emphasize that their value is in the practice of making games. They often demonstrate how accessible game-making is and focus less on the final product. Much like the DIY community, the idea is not that each game is well-crafted but that it is self-crafted. Jammers argue that games can be personal, as an expression of the self, or that game-making is an achievement. They emphasize game value through origin over result.

\section{Games as craft}

The community of game-makers who champion games as craft is similar in spirit to game jamming but smaller in scale. These game-makers champion games as personal expression, as a medium for revolt, or as hand-hewn mass communication. This is most resonant in the work of Anna Anthropy and the workshops for Punk Arcade, but it is also expressed in commercial communities like Game Jolt or in tiny code contests.

\section{Games in galleries}

The value of games is, in part, that they are hand-hewn works in the material of the modern code. These coded artworks are worthy of sharing space with the historical work that we have all come to respect. 


\section{Games in culturally respected forms}

These offer ludic experiences or elements of the game community to make the claim that they belong there. These include the symphonic restyling of game soundtracks or theatrical performances informed by or based on games.

This list is not exhaustive but hints at the wider rhetorical efforts being made to legitimize digital play. These efforts each stand as a basis for their respective arguments about games but are neither unified nor concerted. There are, for example, few organizations that align all such macro-persuasions with a single mission. Instead, what is happening is that these efforts form a chorus that resounds with the heraldry of the value of games. If one feels the needs to defend game-playing or game-making, these provide the evidence that such work is not superfluous.

This raises an important question about the social context under which such a defense must be made: Why is it that so many people feel the need to defend games? Game-playing has existed for a long time, yet now the chorus and efforts to defend them continue to rise.

Is it perhaps that these macro-persuasions are the sociological precedent for legitimate cultural inclusion? Do all such popular efforts need their arguments to be made before they become accepted? And why, in a world where hyper-productivity is championed, do we feel the distinct and persistent need to defend play? Why must play be valuable if it is the opposite of the much-touted work? Why must play have purpose, and why must the organizations that support such play work to defend it? Lastly, why does it seem evident that we have been much more effective at making macro-persuasive arguments around the value of games and play than we have been at actually employing persuasive play?

\section{Games as industrial products}

On the other side of these efforts is the reality that the most substantial work in game-making has come from an industry that sees games very much as product, not artifact. They are more than a commodity because if that is all they are, they would lack the value that we seek to ascribe to them. This is, of course, the great tension between the academic games research community and some professional game-makers. Cultural artifacts are not commoditized. They are not counted in units sold; they are not localized, consumed, discarded, or recycled. In the Western view, culturally valued artifacts are not to be marketed, packaged, shipped, and sold. Yet games are 
all these things and more. For some, games are no different than consumer packaged goods, i.e., ideas come in at one end and then out come a pile of games.

Professional game-makers are not the only community to perceive games as such; there are consumers of games who view them in the same way. There are people seeking persuasive play who also see them like this. If the assumptions of an intellectual property focused on an ideology or technocracy are peeled from the polish of games, there are large communities who would argue that games are nothing more than products. In the most extreme scenario, games could be viewed as less than products and instead as byproducts. They are the byproducts of excesses of creative energy or the superfluous precipitate of idle time. These arguments are largely ignorant of the sociology and psychology of games, but they nevertheless persist.

In the end, it does not matter if the macro-persuasion is for or against games as an artifact or a product. The mere existence of the macro-persuasion indicates its value. Just as there may be games designed to argue for nonviolent resolution, there are also games that make the case for violence. Macro-persuasions for or against games as products or artifacts are merely evidence that the persuasions persist.

At times, the argument goes so far as to hoist a banner that reads 'games matter' in absolute defense of a medium and culture that seemingly argues against those who oppress it. In reality, games are no more oppressed than films and books, with the history of book-burning perhaps trumping the relatively limited censorship of games. Nevertheless, for game academics in particular, what is especially relevant is the need to make the macropersuasion in the pursuit of academic recognition, funding, and research support.

That games matter is baked into every political effort to do something more than just entertain with games. The macro-persuasion, then, is a cultural and political message that necessitates the construction of communities and institutions that support the value of play. These take the form of large-scale exhibitions, with aspirations to garner international respect and legitimacy and political organizations to support games. As with any large entity, the macro-persuasion is comprised of small micro-persuasive game efforts, including the individual game-makers and their efforts that populate these festivals, exhibits, and conferences.

Making macro-persuasions for the value of a product is much harder than doing so for the value of an artifact. So, we persist with games as artifacts. Yet of all the modern digital interactive media efforts, games have been the most successful in completing these efforts in macro-persuasion. Within the 
last ten years, games have completed a macro-persuasive cycle that affirms their cultural value, if not for the individual game then for the community of game-makers and the volume of games.

\section{Micro-persuasions}

On a smaller scale, there is the ever-growing collection of games that aim to persuade. These efforts include advergames, political games, games for change, advocacy games, editorial games, and others. In their sum, these games support the macro-persuasive rhetoric. Simply by their creation, they argue in support of the claim that games can have more than entertainment value. Their claims are evident in their own introductions and their own reasons for being. They argue that it is valuable to experience Native Alaskan culture (Never Alone) and that having a game about Fanta soda (Coca Cola, 2013), or associating the Burger King brand with a suite of mini-Xbox games persuades customers that the franchise is simultaneously hip and whimsical (King Games, 2006).

It is apt to call these games micro-persuasions, in part because most of them are noticeably smaller in their aspirations, budgets, and play length than their non-persuasive counterparts. For those who are unaware of the persuasive game domain, one of the first questions following any such presentation about them is: Why do these games not look like the ones on major consoles?

Of course, these games do not, in part, because the amount of effort and money committed to them is significantly smaller than their profit-making equivalents on game consoles and in stores. When a newspaper or private foundation invests in games, they lay down far less money than the world's leading game-makers.

It is these micro-persuasions that were at the heart of Bogost's original work and generally the notion most in the fore of many people's minds on the intersection of game design and persuasion. It is not uncommon to follow the basic line of thinking that lots of people play games and spend lots of time playing them. As a result, it would be great if someone could harness the power of such entertainment. This is the thinking that drives many into their first foray into micro-persuasive games. The arguments include meeting the audience where they are already engaged (Panic et al., 2013); creating more engaging experiences (Kors et al., 2015); telling better stories (Murray, 2017); or otherwise extending the power of games toward a specific purpose (Kahne et al., 2009). 
Micro-persuasions are the most documented and most apparent of the persuasive game design efforts. Readers are encouraged to review the published findings of others who have outlined the last ten years of persuasive play, specifically Grace (2012) and Humari et al. (2014). The prevalence of research into persuasive and purposeful play (Cater et al., 2014) is also noteworthy.

There are thousands of efforts to persuade through play. The literature demonstrating their success or failure is far less bountiful. In part, much like macro-persuasions, the value is in the making. Educators, for example, know that every first-year English major who is required to write a poem will not become Shakespeare. All the same, the work of trying to fit a verse into an iambic pentameter or to convey meaning in a sonnet is beneficial. It is the process that carries the education, not the final product or artifact. So, too, is the effort in persuasive play. While not every persuasive game is going to move the needle for efficacy, making them substantiates the third rule of macro-persuasions, namely proliferation.

As practitioners, there is a dilemma. It may be evident that practicing such design and implementation is productive, but so, too, is learning to draw, cook, or many other creative endeavors. The core questions should instead be: What is unique and productive when it comes to practicing making persuasive games? Does such work encourage critical thinking of system designs and meaning? Does it inspire more formal thinking about meaning in traditional entertainment? Answering yes to any of these questions engenders a sense of the value of such work and provides those who do it with a reason to continue doing so.

\section{Meta-persuasions, disinformation, and projected fiction as play}

Although much less of a distinct industry than, perhaps, its socio-technical and socio-political contemporaries, there are a variety of small games being played every day with a persuasive aim. These games include the 'fake news' profiteers, the internet trolls, and the champions of a variety of conspiracy theories. Of all the efforts in the persuasive games world, it is these individuals who have perhaps been most effective in terms of persuasive play. They have arguably elected national leaders, toppled viable candidates, and confused nearly every major population with arguments that, at times, even defy logic (Allcot, 2017). This is a combination of make believe, emulation, and fabrication.

This game is a game being played among the technological space that had been created to preserve thought (Leiner et al., 2009) and later evolved 
to become a force that affected democracy (Weare, 2002), sometimes negatively. With purveyors of fake news, for example, the internet functions as a playground in which not everyone understands the games that are being played or who is playing. Voluntary participation has persistently been essential to the definition of games. Games are played willingly, or they are not games. How, then, does fake news fit within such a paradigm? In part, it is because much of our unwitting support of fake news is contextualized within a game context. Fake news is shared via social media, which provides all the feedback systems of a conventional game. Players are encouraged to satisfy, to seek points in the form of likes, and to worry less about being right than being recognized. Fake news and rumor are nothing new, but the scale at which they can be disseminated has not only increased, the motivations for proliferating it have also expanded. Social media provides the ludic environment in which all players, whether producer or proliferator, are rewarded for their efforts. It is a successful gamification of sorts, but one less explicitly designed than resultant.

The results are clearly alarming. There are politicians who believe the number of supporters they have on social media but are unable to tell the difference between a bot and a personal account. There are full-time employees, working in conditions similar to the gold farms of the last decade (Heeks, 2009), who are seeking to produce profitable disinformation in the service of others (Bakir, 2017) or themselves (Sydell, 2016).

Each of these games is being played without the explicit consent of those being played with, but they are also lacking any referee or explicit mandate of opposition. As life goes, you can play a game and can be played with. As the ludic space of social media slips seamlessly into everyday experience, players seem to have lost their ability to identify when they are being played with. Social media images project a life that may not exist or a success when there is none (Hogan, 2010), which is another of the more mundane fake news efforts. Yet those who have engaged in projecting an idealized self on social media are, on a smaller scale, producing fake news. They, like the small armies of disinformation workers, are playing a game of lies with an audience that does not know it is being played with. How can someone who is playing their own game of a projected self be critical of better played and larger-scale games?

Meta-persuasive procedural rhetoric is evidenced in the ways in which these groups achieve their objectives. The meta-games are played with the same toys, blogs, websites, forums, and threads. These players operate within the elements of the game, but they employ them differently. They wreak the most havoc not when they make their own games but when they operate within contexts 
differently. By playing games within games, they wreck half-constructed forms of gamification. By analogy, they are like children playing tag in the middle of a hopscotch game. The disruption is apparent, but the reason is not. The Internet's fluidity and anonymity only expand the shadow of such play, making it seem larger and grander than it is. Yet these players are not master designers or players. They may have played tag through your hopscotch, but now they are playing cards in the middle of someone else's shuffleboard.

One admitted fundamental weakness in understanding meta-persuasive play in this frame is the tension of employed players. As we have come to accept play as voluntary from at least the time of Huizinga forward, the ambiguity of professional play persists. Purveyors of fake news, for example, do not typically view their work as consequential (Sydell, 2016). The fictions they created are just that-fictions. Profitable fictions exist in the way scriptwriters profit from their fiction and animators present worlds that do not really exist. By this framing, fake news production is not a diabolic effort to dismantle democracy; it is a playful way to pay the bills.

Historically, such play has a precedent in the creative play of Big Games (Lantz, 2006) and in the art work of everyone from Situationists (Debord, 1957) to ludic happenings in the 1960 (Berghaus, 1993). The disquieting truth is that fake news bloggers have created more of a stir on their laptops than artists in the 196os ever did on the street. The tools just seem to be more effective now.

More importantly, what these efforts demonstrate is a tendency toward persuasive play in non-game contexts. The games these individuals play have plagued and complicated the daily operations of legitimate news organizations (Waldrop, 2017). It is this efficacy, however detrimental, that demonstrates that persuasive play can work. As case studies, they provide evidence that such play works best when it employs the normal elements of operation-in short, playing within the rules of play but subverting them. In the vernacular, they game the system, and in so doing demonstrate a different way to play. From this perspective, they are similar to micro-persuasion efforts like Critical Gameplay (CriticalGameplay.com) and the work of Molleindustria (MolleIndustria.org). The main difference, as mentioned, is that the games of fake news and social media projections are not always apparent to those who are watching them being played.

\section{Conclusion}

Returning to the wider questions contained in this chapter's introduction, the why for persuasive play becomes apparent. Why do researchers and 
practitioners want to persuade people through games? This is probably because games permeate society at multiple levels, which is demonstrated in everything from political discourse to information manipulation and to the allocation of resources in the pursuit of knowledge. Games work at the macro-level of large-scale systems and institutions, the micro-level of individual play experiences, and the meta-levels between them. Admittedly, there are byproducts at every level that do not always work toward pro-social ends.

Why are games the right medium for delivering persuasive messages? It is likely that they are not the right or wrong medium, because they are less of a medium than a practice with which contemporary society continues to re-engage. Games are played, practiced, tweaked, and redesigned as part of a continued effort to attempt to explain and understand. Adopting the view of games as a medium focuses on the product or artifact of games, which ignores the greater part of persuasive play. Doing so obscures the macro-persuasions, the games within society that propel the medium to something more than a medium. It also misses the meta-persuasions, which employ ludic solutions to achieve their purpose. Whether that purpose is getting more 'likes' on social media or affecting political views, its results are shown in changes in interests, activities, and opinions. The preponderance of selfies with the aim of achieving fame on social media, for example, clearly demonstrates an activity change that outshines any such efforts of a micro-persuasive game. The national entrenchment or nativist sentiments occurring across the world could also likely be the product of a series of opinion-altering meta-persuasions.

Why has the public discourse come to need games as a vehicle for communicating and argumentation? Years ago, the obvious claim was the opportunity for games to explain complex systems, to afford simulation for deep investigations of inquiry-based learning, or simply to meet the experiential demands of changing demographics. Yet the reality is that the depth of engagement is losing out to the shallow experience of social media headlines and easy-to-share infographics. Instead, what persuasive play at all levels demonstrates is that humans operate in game contexts far more often than they may realize. The need for games is not new, but it is more easily identified because of this research into games. Psychology or cell biology have always existed, but our understanding and analysis of them have only occurred relatively recently in human history.

It is, then, more likely that there is no need to gamify because games have always existed. Therefore, persuasive play is less about finding ways to create new persuasive games but is instead a case of appropriately examining, 
identifying, and playing the games that already exist. This is the secret to the success of the great fake news authors and the projectors of social media myths.

Perhaps what is most important is not demonstrating that persuasive play can or cannot work. Instead, we may need to examine or accept the desire to make it work. Perhaps we are seeking something to fill a greater hole? More likely, the persistence of these macro, micro, and meta-persuasions signals an evolution, a revolution, or an apocalypse of media consumption and production habits. Perhaps in another 25 years we will find that we are incapable of understanding an argument without the machinations of play or that arguments presented without play are too simple and antiquated. Much like the death of classical oration, conventional argumentation without the interactive depth of play may seem archaic, clunky, and lacking contemporary nuance. A simple argument may become just that- too simple to be taken seriously.

\section{References}

Allcott, H. \& Gentzkow, M. (2017). Social Media and Fake News in the 2016 Election. Journal of Economic Perspectives, 31(2), 211-236. doi:10.3386/w23089.

Arnett, J.J. (2002). The Psychology of Globalization. American Psychologist, $57(10)$, 774. doi: 10.1037/0003-066X.57.10.774.

Bakir, V. \& McStay, A. (2017). Fake News and The Economy of Emotions: Problems, Causes, Solutions. Digital Journalism, 6(2), 154-175. https://doi.org/10.1080/2167 0811.2017.1345645.

Berghaus, G. (1993). Happenings in Europe in the '6os: Trends, events, and leading figures. TDR (1988-), 37(4), 157-168. doi: 10.2307/1146300.

Bogost, I. (2007). Persuasive Games: The Expressive Power of Videogames. Cambridge, MA: MIT Press.

—. (2012). G4C13 Keynote. Youtube. Retrieved 2 July 2018 from https://www. youtube.com/watch?v=GBduFJUdoog.

Boyle, E.A., Hainey, T., Connolly, T.M., Gray, G., Earp, J., Ott, M., Lim, T., Ninaus, M., Ribeiro, C., \& Pereira, J. (2016). An Update to the Systematic Literature Review of Empirical Evidence of the Impacts and Outcomes of Computer Games and Serious Games. Computers \& Education, 94 (March 2016), 178-192. https://doi. org/10.1016/j.compedu.2015.11.003.

Carter, M., Downs, J., Nansen, B., Harrop, M., \& Gibbs, M. (2014). Paradigms of Games Research in HCI: A Review of 10 Years of Research at CHI. In Proceedings of the First ACM SIGCHI Annual Symposium on Computer-Human Interaction in Play, 27-36. New York, NY: ACM Press. https://doi.org/10.1145/2658537.2658708. 
Chess, S., \& Shaw, A. (2015). A Conspiracy of Fishes, or, How We Learned to Stop Worrying About\# Gamergate and Embrace Hegemonic Masculinity.Journal of Broadcasting \& Electronic Media, 59(1), 208-220. https://doi.org/10.1080/08838 151.2014.999917.

Cialdini, R.B. (1987). Influence: The Psychology of Persuasion. New York, NY: Collins Business Essentials.

Coca Cola (2013). Fanta Fruit Slam 2. [Android Game].

Corneliussen, H. \& Rettberg, J.W. (eds.). (2008). Digital Culture, Play, and Identity: A World of Warcraft reader. Cambridge, MA: MIT Press.

De Lange, M. (2015). The Playful City: Using Play and Games to Foster Citizen Participation. In A. Skaržauskienè (ed.), Social Technologies and Collective Intelligence, pp. 426-434. Kaunas, Lithuania: Mykolas Romeris University.

Debord, G. (1957). The Situationists and the New Forms of Action in Politics and Art. On the Passage of a Few People Through a Rather Brief Moment in Time. In McDonough (ed.), The Situationist International. Cambridge, MA: MIT Press.

Demby, E. (2011). Psychographics and From Whence It Came. Decatur, Georgia: Marketing Classics Press.

Duncan, S.C. (2011). Minecraft, Beyond Construction and Survival. Well Played: A Journal on Video Games, Value and Meaning, 1(1), 1-22. https://doi.org/10.1184/ R1/10029221.v1.

Entertainment Software Association (2016). Sales, Demographic, and Usage Data: Essential Facts About the Computer and Video Game Industry. $E S A$. Retrieved 25 July 2018 from https://techraptor.net/gaming/news/ esa-releases-2016-essential-facts-report.

Gee, J.P. (2004). Learning by Design: Games as Learning Machines. E-Learning and Digital Media, 2(1), 5-16. https://doi.org/10.2304/elea.2005.2.1.5.

Grace, L. (2012). A Topographical Study of Persuasive Play in Digital Games. In Proceedings of the Academic Mindtrek (Tampere, Finland, 3-5 October 2012). New York, NY: ACM Press.

Grace, L.D. (2017). Heuristics from Curating and Exhibiting Game Art in the 21st Century. In ARTECH2017: Proceedings of the 8th International Conference on Digital Arts. https://doi.org/10.1145/3106548.3106607.

-., \& Farley, M. (2016). How Game Design Thinking Becomes Engagement Design. In Proceedings of the 2oth International Academic Mindtrek Conference, 281-286. New York, NY: ACM Press.

Greenfield, P.M. (1994). Video Games as Cultural Artifacts. Journal of applied developmental psychology, 15(1), 3-12. https://doi.org/10.1016/0193-3973(94)90003-5. Hamari, J., Koivisto, J., \& Pakkanen, T. (2014). Do Persuasive Technologies Persuade? A Review of Empirical Studies. In International Conference on Persuasive Technology, 118-136. Cham, Switzerland: Springer International Publishing AG. 
Heeks, R. (2009). Understanding "Gold Farming” and Real-Money Trading as The Intersection of Real and Virtual Economies. Journal for Virtual Worlds Research, 2(4). https://doi.org/10.4101/jvwr.v2i4.868.

Hogan, B. (2010). The Presentation of Self in the Age of Social Media: Distinguishing Performances and Exhibitions Online. Bulletin of Science, Technology \& Society, 3o(6), 377-386. https://doi.org/10.1177/0270467610385893.

Jenkins, H. (2005). Games, the New Lively Art. In Raessens, J. \& J. Goldstein (eds.), Handbook of Computer Game Studies, 175-189. Cambridge, MA: MIT Press.

Kahne, J., Middaugh, E., \& Evans, C. (2009). The Civic Potential of Video Games. Cambridge, MA: MIT Press.

King Games (2006). Sneak King [Xbox Game].

King, B., Borland, J., \& Stewart, R. (2003). Dungeons and Dreamers: The Rise of Computer Game Culture from Geek to Chic. New York, NY: McGraw-Hill/ Osborne. Kors, M., Van der Spek, E.D., \& Schouten, B.A. (2015). A Foundation for the Persuasive Gameplay Experience. In Proceedings of the Foundations of Digital Games. Retrieved 12 May 2018 from http://www.fdg2015.org/papers/fdg2015_paper_28. pdf.

Lantz, F. (2006). Big Games and the Porous Border Between the Real and the Mediated. Vodafone Receiver Magazine, 16. Retrieved 1 February 2017 from: http:// www.receiver.vodafone.com/16/articles/indexo7.html.

Leiner, B.M., Cerf, V.G., Clark, D.D., Kahn, R.E., Kleinrock, L., Lynch, D.C., Postel, J, Roberts, L.G., \& Wolff, S. (2009). A BriefHistory of the Internet. ACM SIGCOMM Computer Communication Review, 39(5), 22-31. http://doi.acm.org/10.1145/1629607.1629613.

Murray, J.H. (2017). Hamlet on the Holodeck: The Future of Narrative in Cyberspace. Cambridge, MA: MIT press.

Nath, T. (2016). Investing in Video Games: This Industry Pulls in More Revenue Than Movies, Music. Nasdaq. Retrieved 3 April 2019 from: http://www.nasdaq. com/article/investing-in-video-games-this-industry-pulls-in-more-revenuethan-movies-music-cm634585.

E-Line Media (2014). Never Alone [Digital Game].

Panic, K., Cauberghe, V., \& De Pelsmacker, P. (2013). Comparing TV Ads and Advergames Targeting Children: The Impact of Persuasion Knowledge on Behavioral Responses. Journal of Advertising, 42(2-3), 264-273. https://doi.org/10.1080/oo9 13367.2013.774605.

Parkin, S. (2014). Gamergate: A Scandal Erupts in the Video-Game Community. The New Yorker, 17. Retrieved 3 March 2018 from https://www.newyorker.com/tech/ annals-of-technology/gamergate-scandal-erupts-video-game-community.

Plummer, J.T. (1974). The Concept and Application of Lifestyle Segmentation. The Journal of Marketing, 38(1), 33-37. doi: 10.2307/1250164. 
Salter, M. (2017). From Geek Masculinity to Gamergate: The Technological Rationality of Online Abuse. Crime, Media, Culture, 14(2), 247-264. https://doi. org/10.1177/1741659017690893.

Squire, K. (2011). Video Games and Learning: Teaching and Participatory Culture in the Digital Age. New York, NY: Teachers College Press.

Sydell, L. (2016). We Tracked Down a Fake-News Creator in the Suburbs. Here's What We Learned. All Tech Considered. Retrieved 7 April 2018 from https://www.npr.org/sections/alltechconsidered/2016/11/23/503146770/ npr-finds-the-head-of-a-covert-fake-news-operation-in-the-suburbs.

Waldrop, M.M. (2017). News Feature: The Genuine Problem of Fake News. Proceedings of the National Academy of Sciences, 114(48), 12631-12634. https://doi. org/10.1073/pnas.1719005114.

Weare, C. (2002). The Internet and Democracy: The Causal Links Between Technology and Politics. International Journal of Public Administration, 25(5), 659-691. https://doi.org/10.1081/PAD-120003294.

Wikia (2017). World of Warcraft. Retrieved 8 March 2018 from http://wowwiki. wikia.com/wiki/Portal:Main, last accessed on 14/12/2018.

Xu, Y., Cao, X., Sellen, A., Herbrich, R., \& Graepel, T. (2011,). Sociable Killers: Understanding Social Relationships in an Online First-Person Shooter Game. In Proceedings of the ACM 2011 conference on Computer supported cooperative work, 197-206. New York, NY: ACM Press. https://doi.org/10.1081/PAD-120003294.

\section{About the author}

Lindsay Grace is the Knight Chair of Interactive Media at the University of Miami. He was founding director of the American University Game Lab and Studio where he piloted more half a million dollars in persuasive game design in three years. His game designs have received awards from the Games for Change Festival, Meaningful Play, and others. 
